\section{Vertical and Horizontal Misfit Analysis of 3-unit FDP Fabricated with Different Techniques and CAD/CAM Systems}

Eduardo Piza Pellizzer11, Caroline Cantieri de Mello1, Jéssica Marcela de Luna Gomes ${ }^{1}$, Joel Ferreira Santiago Júnior 2, Cleidiel Aparecido Araújo Lemos Fellippo Ramos Verri1
'Department of Dental Materials and Prosthodontics, Araçatuba Dental School, UNESP - Universidade Estadual Paulista, Araçatuba, Brazil ${ }^{2}$ Pró-Reitoria de Pesquisa e Pós-graduação (PRPPG), USC - Universidade do Sagrado Coração, Bauru, SP, Brazil

Correspondence: Eduardo Piza Pellizzer, Rua José Bonifácio, 1193, 16015-050 Araçatuba, SP, Brasil. Tel: +55-18-36363297. e-mail: ed.pl@uol.com

\begin{abstract}
The aim of this is was evaluate the vertical and horizontal marginal adaptation of 3-unit fixed partial denture frameworks fabricated using different techniques and CAD/CAM systems. A total of 40 framework specimens were fabricated and divided into four groups as follows: lost-wax casting (G1); lost-wax casting with welding (G2); extraoral optical scanning of models (3S/DWOS) (G3); intraoral optical scanning (Cerec Bluecam/Sirona) (G4). A reference model was used to simulate a fixed partial denture with three elements (with a central pontic). The frameworks of $\mathrm{G} 1$ and $\mathrm{G} 2$ were cast in nickel-chromium $(\mathrm{NiCr})$ alloy, whereas those of $\mathrm{G} 3$ and $\mathrm{G} 4$ were milled in zirconia. In all groups, vertical and horizontal marginal adaptation (over-contour and under-contour) was evaluated using a three-dimensional optical microscope (Quick Scope, Mitutoyo). The results showed higher vertical marginal misfit in $\mathrm{G} 1$ than in the other groups $(p<0.001)$. Regarding horizontal marginal misfit, higher over-contour values occurred in $\mathrm{G} 3$ than in the other groups $(p<0.001)$. G3 did not show under-contour at all, whereas the other groups did not differ from each other in this regard ( $p>0.05$ ). Within the limitations of this study, it can be concluded that lost-wax casting with welding is a viable alternative to the use of CAD/CAM systems to fabricate frameworks of three-unit FPDs, since the techniques yielded similar vertical misfit values. Extra-oral CAD/CAM systems showed the highest horizontal misfit (over-contour) compared to other groups.
\end{abstract}

Key Words: Marginal adaptation, misfit, CAD/CAM, dental soldering, welding.

\section{Introduction}

The marginal misfit of fixed partial dentures (FPDs) corresponds to the marginal gap between the edge of the prosthetic restoration and the limit of the tooth preparation (1). Marginal misfit contributes to cement exposure in the oral environment, with the possibility of dissolution, plaque accumulation (2), and secondary caries. These effects compromise both the longevity of the prosthesis and periodontal health (2). Usually, a number of factors lead to marginal misfit, and the technique used to manufacture the prosthesis is one such factor (3).

The lost-wax casting technique was considered the gold standard in dentistry in the 20th century (4). However, this technique is highly sensitive due to the possibility of distortion degree (approximately $100 \mu \mathrm{m}$ ) (5), caused by different factors that can occur during investment, wax removal, casting, finishing and polishing for conventional casting (6). Some authors have recommended minimizing these distortions in FPDs by welding the framework joints. This can improve the fit and passivity of prostheses (7). Indeed, in a systematic review, Abduo et al. (8) reported that welding the frameworks corrects the discrepancies yielded by the lost-wax casting technique.

Recently, computer-aided design and manufacturing
(CAD/CAM) have become increasingly available. The model can be obtained through intraoral scanning and extra oral image acquisition (9). These techniques have simplified manufacturing and contributed to the use of more aesthetic materials such as zirconia, as an alternative to metal alloys (10). A recently systematic review reported that CAD/ CAM systems, virtual design, and computer-controlled milling can result in better fit between the copings and the prepared tooth in comparison with conventional method (lost-wax casting) (1). However, there is a lack of studies that compare CAD/CAM system compared to lost wax technique with welding joint in terms of marginal fit (vertical and horizontal marginal adaptation).

Studies have compared CAD/CAM systems with the lost-wax technique $(11,12)$, while others have compared the lost-wax technique with and without welding (2). However, there are absence of studies have compared marginal fit (vertical and horizontal marginal adaptation) between CAD/CAM systems and the lost-wax technique with welded joints. Thus, the aim of the present study was to evaluate the vertical and horizontal marginal adaptation of three-unit, fixed dental prostheses fabricated using different techniques. The null hypothesis was that there is no difference in vertical and horizontal marginal misfit 
between lost-wax casting (with or without welding joint) and CAD/CAM systems (3S or Cerec).

\section{Material and Methods}

Thirty specimens were obtained and divided into three groups $(\mathrm{n}=10)$ distributed into $\mathrm{G} 1, \mathrm{G} 3$ and $\mathrm{G} 4$. After analysis of vertical and horizontal marginal misfit the specimens of $\mathrm{G} 1$ were submitted to laser welding of frameworks obtaining the $\mathrm{G} 2$ for vertical and horizontal measurements.

A reference model was fabricated to simulate a threeunit fixed dental prostheses of a mandibular first premolar fixed to a first molar with a central pontic (teeth 44 to 46). The reference model was design with a full crown restoration of a $0.6-\mathrm{mm}$, a $360^{\circ}$ chamfer with $3^{\circ}$ of total occlusal convergence, a height of 5.5 , and a diameter of $7.5 \mathrm{~mm}$ for the molar and $4.5 \mathrm{~mm}$ for premolar (Fig. 1A). Approximately $1.5 \mathrm{~mm}$ below the chamfer, the reference model presented 24 predetermined points. In this way, the measurement points were standardized across all specimens (Fig. 1B).

Twenty impressions of the reference model were made with Elite HD Putty Soft Normal Setting (Zhermack S.p.A., Badia Polesine, Rovigo, Italy) and Elite H-D Light Body Normal Setting (Zhermack S.p.A., Badia Polesine). In this way, 20 molds were obtained. Each mold was sprayed with a surface tension reducer (Surfacer ${ }^{\circledast}$, Polidental Ind. And Com. Ltda) and then filled with gypsum stone type IV (Elite Rock Thixotropic, Zhermack SpA, Baida Polesine). These models were distributed into $\mathrm{G} 1$ (lost-wax technique) and G3 (3S extraoral CAD/CAM system).

The frameworks in $\mathrm{G} 1$ were made using monoblock
$\mathrm{NiCr}$ casting (without beryllium) (Fit cast-SB Plus, Talmax, Curitiba, PR, Brazil). After analysis of the vertical and horizontal marginal adaptation for the $\mathrm{G1}$, the samples were sectioned using a carborundum disc at the central pontic between the first and second premolars. (Ninja Gold - $\emptyset 25 \times 0,7$ mm, Talmax, Curitiba, PR). The sections were then attached using acrylic resin (Duralay ${ }^{\circledast}$ (Reliance Dental Mfg. Co., Alsip, IL, USA) for laser welding of frameworks. After the framework had been welded, to obtain the $G 2$ measurements, the vertical and horizontal marginal misfits were evaluated again.

The frameworks in G3 were made using scans of each gypsum models, a total of 10 scans and these were taken using the extraoral CAD/CAM system (3S, Dental Wings). The scans were performed by delimiting the margin of the tooth preparations. The images obtained allowed the researchers to design the infrastructure. The frameworks in G4 were made using direct scans of the reference model. These scans were obtained using the Cerec AC Bluecam virtual system (Sirona, Salzburg, Österreich, Austria) which emplys CEREC Optispray contrast powder (Sirona, Salzburg, Österreich, Austria), simulating the intra-oral CAD/CAM system technique.

In $\mathrm{G} 3$ and $\mathrm{G} 4$, the virtual planning data were sent to Conexão Sistemas de Próteses industrial center (Conexão Sistema de Próteses, São Paulo, SP, Brazil) and the frameworks were manufactured by an industrial milling machine Conexão CAD/CAM Precision System (Conexão Sistema de Próteses). In this way, a monoblock zirconia framework was milled (VITA Zahnfabrik H. Rauter GmbH \&t Co. KG, Bad Sackingen, Baden-Wurttermberg, Germany).
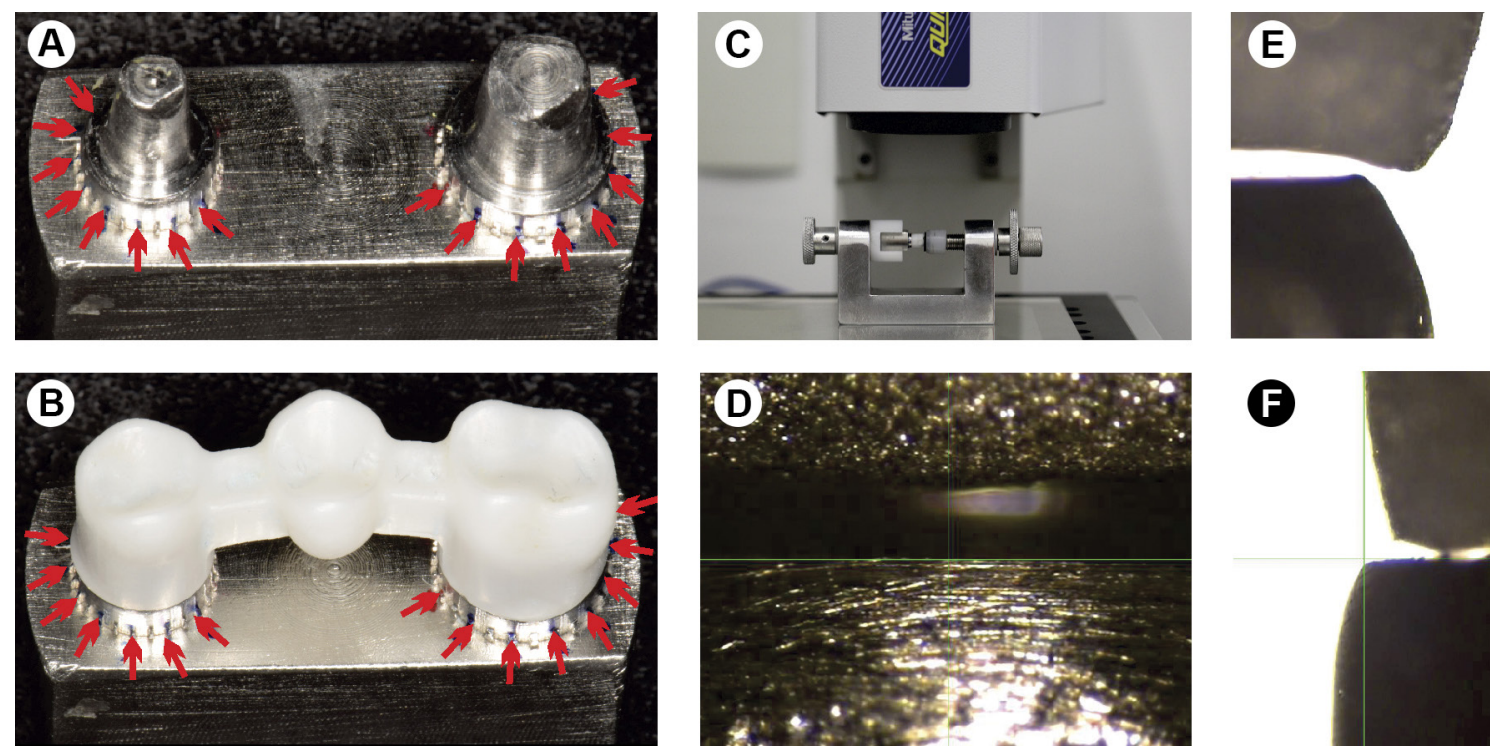

Figure 1. (A) Reference model simulating a 3-unit- FDP; (B) Points to reference the measurements with the framework in position; (C) Framework position in the microscopy for analysis; (D) Microscopy image of marginal vertical misfit (x350 magnification); (E) Microscopy image of horizontal marginal misfit (over-contour) (x350 magnification); (F) Microscopy image of horizontal marginal misfit (under-contour) (x350 magnification). 
Sintering was carried out in an oven (HTC Speed, Sirona, Salzburg, Osterreich, Austria) at $1500^{\circ} \mathrm{C}$ for $2 \mathrm{~h}$ and $20 \mathrm{~min}$.

Vertical marginal misfit was analyzed at 12 points for each crown totaling 960 measurements, while horizontal marginal misfit was analyzed at eight points per crown along the interface of the reference model/framework totaling 640 measurements. The analysis was performed using a three-dimensional optical microscope (Quick Scope, Mitutoyo, Chicago, IL, USA) with a digital table that had a $350 \times$ zoom and a precision of $1 \mu \mathrm{m}$ (Fig. 1C). The measurements were determined using OSPAK software (Mitutoyo). The values for vertical misfit (Fig. 1D) and horizontal marginal misfit (over-contour) (Fig.1E) and horizontal marginal misfit (under-contour) (Fig. 1F) were obtained in millimeters and converted into micrometers.

After analysis of the individual groups, the data were confirmed in intra-examiner variability. A new analysis of some samples was performed by the same operator for vertical and horizontal marginal misfit to verify the calibration of operator, calculated by the specific correlation test $(r)$ and random error analysis (Dahlberg) $(p<0.05)$.

Data from the measurements were organized in Excel (Microsoft Office Excel, Redmond, WA, United States) and entered SigmaPlot software (SigmaPlot, San Jose, CA, USA). After normality was confirmed by Shapiro-Wilk test twoway ANOVA (Factors: Manufacturing technique, Tooth) with a post-hoc Tukey's test was used to indicate the differences between the groups. The significance level was set at 5\%.

\section{Results}

The specific correlation test ( $r$ ) showed an agreement of $r=0.98$ for the vertical marginal misfit, in the systematic error no difference observed between the samples in the analyzed periods (paired t-test $=1.177 ; p=0.242$ ), the random error test (Dahlberg) $\pm 10 \mu \mathrm{m}$. Regarding horizontal marginal misfit, the specific correlation test $(r)$ showed an agreement of 0.91 with no difference between the readings (paired $t=0.234, p=0.816$ ), the random error test (Dahlberg) $\pm 20 \mu \mathrm{m}$.

In the vertical marginal analysis, highest vertical misfit was observed for $\mathrm{G} 1$, being significantly different to other groups $(p<0.001)$. However, no significant difference was observed among G2, G3 and G4 (p>0.05) (Fig.2)

In the analysis of positive horizontal marginal misfit (over-contour), a significant difference was observed among all groups $(p<0.001)$. The highest value of overcontour misfit was observed in $\mathrm{G} 3$, which differed significantly from the other groups $(p<0.001)$. Furthermore, a significant difference was observed between $\mathrm{G} 2$ (mean: 0.108 ) and $G 4$ (mean: $0.0805 ; p=0.027$ ). However, there was no difference between $\mathrm{G} 2$ and $\mathrm{G} 1$ ( $\mathrm{p}=0.196)$, or between and $\mathrm{G} 1$ and $\mathrm{G} 4(\mathrm{p}=0.824 ; \alpha=1.0)$ (Fig. 3). In the analysis of negative horizontal misfit (under-contour), no data were reported from G3. Among the other groups, no significant difference occurred ( $p=0.244$ ) (Fig. 4).

\section{Discussion}

The null hypothesis was rejected since difference were observed in the vertical and horizontal (over-contour) misfit. Regarding vertical misfit, the lost-wax cast (G1) showed the highest vertical marginal discrepancy among

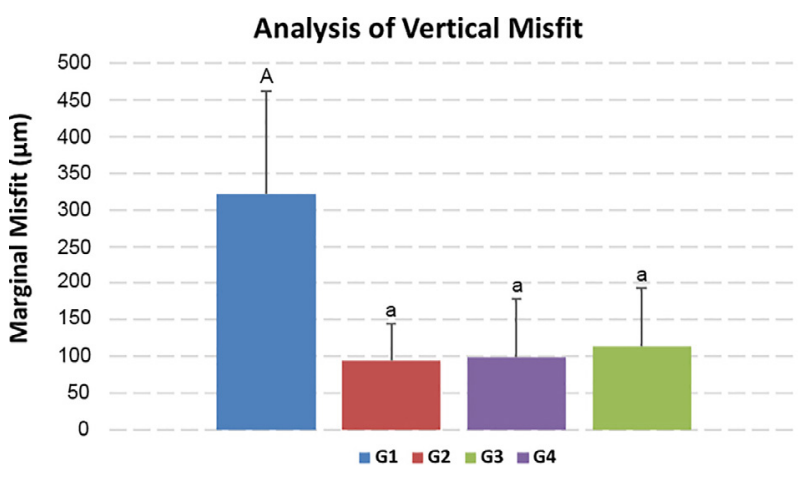

Figure 2. Analysis of marginal vertical misfit (A,a: $\mathrm{p}<0.05 / \mathrm{a}, \mathrm{a}: \mathrm{p} \geq 0.05)$.

\section{Positive Horizontal Misfit (Over-Contour)}

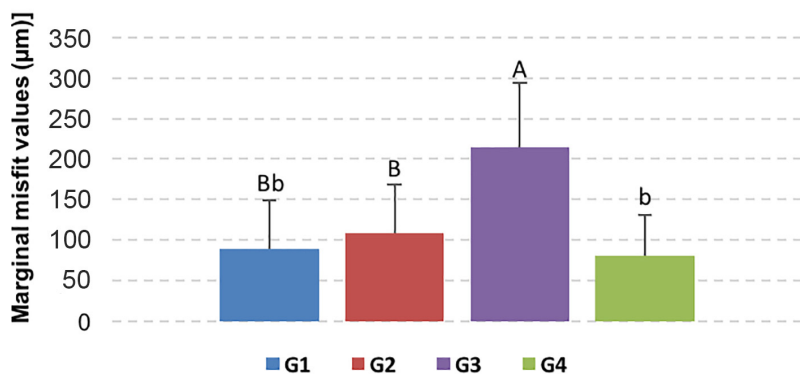

Figure 3. Negative horizontal misfit (over-contour) (A,b;A,B;B,b: $\mathrm{p}<0.05$ / $\mathrm{B}, \mathrm{B}: \mathrm{p} \geq 0.05$ ).

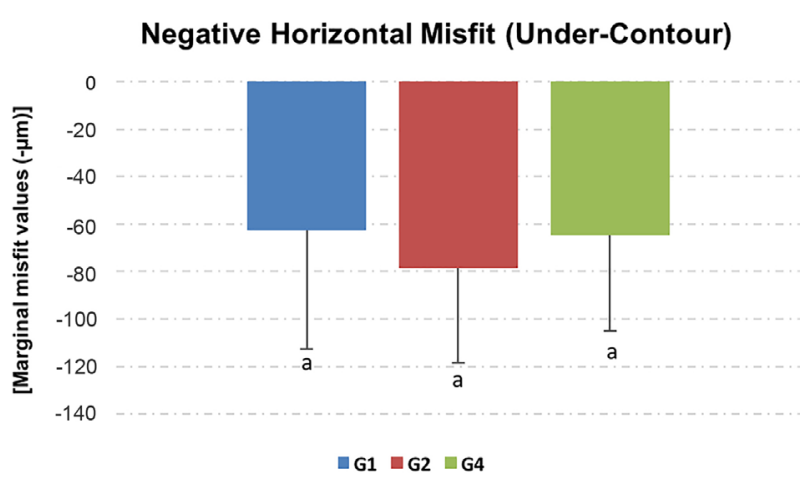

Figure 4. Negative horizontal misfit (under-contour) (a,a: $p \geq 0.05$ ) 
all groups. These results corroborated those of previous studies $(1,9,12)$. The mean vertical marginal misfit value in the lost-wax casting group (G1) was $322 \mu \mathrm{m}$. This was considered clinically unacceptable, whereas the mean vertical misfit in G2 $(95.1 \mu \mathrm{m}), \mathrm{G} 3(98.6 \mu \mathrm{m})$, and G4 (114 $\mu \mathrm{m})$ were lower and within the clinical limit of $120 \mu \mathrm{m}$ established in the literature (1). Thus, lost wax casting with welding (G2) showed vertical misfit similar to CAD/CAM system ( $\mathrm{G} 3$ e $\mathrm{G} 4$ ) perhaps because the welding technique reduces the effects of expansion and metal coating (2) thus reducing distortion and leading to a more precise adaptation procedure (13). Therefore, even though it retains the possibility of human error (14) this technique provides better vertical marginal adaptation than lost-wax casting without welding (15).

On the other hand, CAD/CAM systems require fewer framework fabrication steps than lost-wax casting, thus minimizing errors (12). In a systematic review, Boitelle et al. (1) showed that CAD/CAM systems yield better adaptation than the lost-wax technique without welding, supporting the findings of the present study. However, when the extraoral (Group 3) and intraoral (Group 4) CAD/CAM system groups were compared, there was no difference between them in terms of vertical marginal adaptation. Similar results were found in other studies $(16,17)$.

Regarding horizontal misfit, G3 (extra-oral CAD/CAM system) presents significantly horizontal over-contour misfit compared to other groups, with no reported undercontour horizontal misfit. The results of this technique (extra-oral CAD/CAM system) can be influenced by adding more clinical steps with the use of different materials (18) to obtain the model, and this may contribute to dimensional changes and to affect the fit of framework. In this study, although $\mathrm{G} 1$ and $\mathrm{G} 2$ presented a different technique for obtaining the framework, the groups used the same materials (impression material and gypsum) to obtain the model. However, the lost-wax casting (unlike the digital technique) allows for manual control of any over-contour of the framework. In addition, another possibility is related to different framework material, since the metal alloy contraction after the casting could reduce the overextension of the framework (19).

Furthermore, CAD/CAM systems generally use zirconia in the pre-sintered stage (20), causing a dimensional alteration of up to $20 \%$ in the frameworks (21). However, the low values of over-contour observed in the $\mathrm{G} 4$ can be justified by the greater precision system since all steps are digital (intraoral) allowing favorable results even with the dimensional alteration of the zirconia (22). In addition, it is important to emphasize that the over-contour misfit should be avoided whenever possible because it is considered the worse situation due to the greater potential for plaque accumulation (23)

The frameworks in $\mathrm{G} 2$ were modified from those in $\mathrm{G} 1$, and there was no difference between the groups in terms of either over-contour or under-contour horizontal marginal adaptation, indicating that welding does not interfere with the horizontal adaptation of the frameworks. In G2, there was significantly higher mean over-contour horizontal marginal misfit than in $\mathrm{G} 4$. These data corroborate previous studies $(24,25)$ and may be related to the precision of the intraoral CAD/CAM system, which presents more acceptable results of shadow, contour, marginal adaptation, and occlusion of copings. Furthermore, the use of contrast powder improves scanning accuracy and consequently coping adaptation $(1,18)$.

In the present study, we tried to eliminate bias by following the procedures recommended by the manufacturers. That is, the FPD frameworks were fabricated in accordance with each CAD/CAM system or lost-wax casting technique (with or without welding). Thus, this work sought through the groups to represent different clinical situations that are routinely encountered. However, even though it mirrored the behavior of the daily clinic, some limitations must be cited such as the different methods of obtaining frameworks (lost-wax casting; extraoral and intraoral CAD/CAM system), and different materials (Zirconia and $\mathrm{NiCr}$ ), which could influence the results obtained. In addition, this in vitro study does not replicate gingival bleeding, saliva, or limited access to the preparations. Further studies are recommended to evaluate the misfit of frameworks based on the standardization of these variables.

Thus, despite the limitations of this in vitro study, we concluded that lost wax casting with welding is a viable alternative to $C A D / C A M$ systems to fabricate frameworks of three-unit FPDs, since the techniques yielded similar vertical misfit values. Extra-oral CAD/CAM system showed highest horizontal misfit (over-contour) compared to other groups.

\section{Acknowledgements}

This study was supported by the São Paulo State Research Foundation (FAPESP): 2011/19150-7.

\section{Resumo}

0 objetivo deste estudo foi avaliar a adaptação marginal vertical e horizontal de infraestruturas de prótese fixas de três elementos confeccionadas por diferentes técnicas e diferentes sistemas CAD/CAM. Um total de 40 infraestruturas foram confeccionadas e divididas em quatro grupos: fundição por cera perdida (G1); fundição por cera perdida com ponto de solda (G2); escaneamento óptico extraoral para escaneamento do modelo (3S/DWOS); escaneamento óptico intraoral (Cerec Bluecam/ Sirona) (G4). Uma matriz metálica foi utilizada para simular uma prótese fixa de três elementos (com pôntico central). As infraestruturas do G1 e $\mathrm{G} 2$ foram fundidas em liga metálica de níquel-cromo $(\mathrm{NiCr})$, enquanto que as infraestruturas de G3 e G4 foram fresadas em zircônia. Todos os 
grupos foram analisados quanto à adaptação marginal vertical e horizontal (sobrecontorno e subcontorno) em microscópio óptico tridimensional (Quick Scope, Mitutoyo). Os resultados apresentaram maiores valores de desadaptação marginal vertical no $\mathrm{G} 1$ comparados aos outros grupos $(p<0,001)$. Em relação a desadaptação marginal horizontal, maiores valores de sobrecontorno foram observado no $\mathrm{G} 3$ em comparação com os demais grupos $(p<0,001)$. Não foi observado valores de subcontorno para o $G 3$, enquanto que os demais grupos não apresentaram diferença significante para o subcontorno $(p>0,05)$. Dentro das limitações do presente estudo, pode-se concluir que a técnica convencional após ponto de solda é uma alternativa viável para confecção de infraestruturas de próteses fixas de três elementos comparado ao uso de sistemas CAD/CAM, uma vez que as técnicas apresentaram valores de adaptação marginal vertical similares. Os sistemas CAD/CAM extraoral apresentou o maior desajuste horizontal (sobrecontorno) em comparação com outros grupos.

\section{References}

1. Boitelle P, Mawussi B, Tapie L, Fromentin 0 A systematic review of CAD/ CAM fit restoration evaluations. J Oral Rehabil 2014;41:853-874.

2. Jei JB, Mohan J Comparative Evaluation of Marginal Accuracy of a Cast Fixed Partial Denture Compared to Soldered Fixed Partial Denture Made of Two Different Base Metal Alloys and Casting Techniques: An In vitro Study. J Indian Prosthodont Soc 2014;14:104-109.

3. Kahramanoglu E, Kulak-Ozkan Y Marginal and internal adaptation of different superstructure and abutment materials using two different implant systems for five-unit implant-supported fixed partial dentures: an in vitro study. Int J Oral Maxillofac Implants 2013;28:1207-1216.

4. Zarauz C, Valverde A, Martinez-Rus F, Hassan B, Pradies G Clinical evaluation comparing the fit of all-ceramic crowns obtained from silicone and digital intraoral impressions. Clin Oral Investig 2016;20:799-806.

5. Schiffleger BE, Ziebert GJ, Dhuru VB, Brantley WA, Sigaroudi K Comparison of accuracy of multiunit one-piece castings. J Prosthet Dent 1985;54:770-776.

6. de Franca DG, Morais MH, das Neves FD, Carreiro AF, Barbosa GA Precision Fit of Screw-Retained Implant-Supported Fixed Dental Prostheses Fabricated by CAD/CAM, Copy-Milling, and Conventional Methods. Int J Oral Maxillofac Implants 2017;32:507-513.

7. Alhashim A, Kamel M, Brackett WW Four-year follow-up of the rehabilitation of a mandibular arch with a cementable zirconiareinforced fixed dental prosthesis: a clinical report. J Prosthet Dent 2012;108:138-142.

8. Abduo J, Lyons K, Bennani V, Waddell N, Swain M Fit of screwretained fixed implant frameworks fabricated by different methods: a systematic review. Int J Prosthodont 2011;24:207-220.

9. Mello C, Santiago Junior JF, Galhano G, Quinelli Mazaro JV, Scotti R, Pellizzer E Analysis of vertical marginal adaptation of zirconia fixed dental prosthesis frameworks fabricated by the CAD/CAM System: A Randomized, Double-Blind Study. Int J Prosthodont 2016;29:157-160.

10. Miyazaki T, Hotta Y CAD/CAM systems available for the fabrication of crown and bridge restorations. Aust Dent J 2011;56 Suppl 1:97-106.

11. Gunsoy S, Ulusoy M Evaluation of marginal/internal fit of chrome- cobalt crowns: Direct laser metal sintering versus computer-aided design and computer-aided manufacturing. Niger J Clin Pract 2016;19:636-644.

12. Ortorp A, Jonsson $D$, Mouhsen A, Vult von Steyern $P$ The fit of cobalt-chromium three-unit fixed dental prostheses fabricated with four different techniques: a comparative in vitro study. Dent Mater 2011;27:356-363.

13. Byrne $G$ Soldering in prosthodontics--an overview, part I. J Prosthodont 2011;20:233-243.

14. Malo $P$, de Araujo Nobre M, Borges J, Almeida R Retrievable metal ceramic implant-supported fixed prostheses with milled titanium frameworks and all-ceramic crowns: retrospective clinical study with up to 10 years of follow-up. J Prosthodont 2012;21:256-264.

15. Presotto AG, Bhering $C L$, Mesquita MF, Barao VA Marginal fit and photoelastic stress analysis of CAD-CAM and overcast 3-unit implantsupported frameworks. J Prosthet Dent 2017;117:373-379.

16. Schonberger J, Erdelt KJ, Baumer D, Beuer F Marginal and internal fit of posterior three-unit fixed zirconia dental prostheses fabricated with two different CAD/CAM systems and materials. Clin Oral Investig 2017.

17. Lee KB, Park CW, Kim KH, Kwon TY Marginal and internal fit of allceramic crowns fabricated with two different CAD/CAM systems. Dent Mater J 2008;27:422-426.

18. Shembesh $M$, Ali $A$, Finkelman $M$, Weber $H P$, Zandparsa $R$ An In Vitro Comparison of the Marginal Adaptation Accuracy of CAD/CAM Restorations Using Different Impression Systems. J Prosthodont 2016.

19. Bhering CL, Takahashi JM, Luthi LF, Henriques GE, Consani RL, Mesquita MF Influence of the casting technique and dynamic loading on screw detorque and misfit of single unit implant-supported prostheses. Acta Odontol Scand 2013;71:404-409.

20. Denry I, Kelly JR State of the art of zirconia for dental applications. Dent Mater 2008;24:299-307.

21. Buchi DL, Ebler S, Hammerle CH, Sailer I Marginal and internal fit of curved anterior CAD/CAM-milled zirconia fixed dental prostheses: an in-vitro study. Quintessence Int 2014;45:837-846.

22. Pedroche LO, Bernardes SR, Leao MP, Kintopp CC, Correr GM, Ornaghi BP Marginal and internal fit of zirconia copings obtained using different digital scanning methods. Braz Oral Res 2016;30:e113.

23. Neves FD, Prado CJ, Prudente MS, Carneiro TA, Zancope K, Davi LR Micro-computed tomography evaluation of marginal fit of lithium disilicate crowns fabricated by using chairside CAD/CAM systems or the heat-pressing technique. J Prosthet Dent 2014;112:1134-40.

24. Prudente MS, Davi LR, Nabbout KO, Prado CJ, Pereira LM, Zancope K Influence of scanner, powder application, and adjustments on CADCAM crown misfit. J Prosthet Dent 2017.

25. Baig MR, Gonzalez MA, Abu Kasim NH, Abu Kassim NL, Farook MS. Effect of operators' experience and cement space on the marginal fit of an in-office digitally produced monolithic ceramic crown system. Quintessence Int 2016;47:181-191. 